\title{
La Relación Sujeto/Máquina como Productora de Subjetividades
}

\section{The Subject/Machine Relationship as a Producer of Subjectivities}

\author{
Yasna Valenzuela Román* \\ Universidad Santo Tomás de Chile
}

(Recepción: Marzo 2004 - Aceptación: Junio 2004)

\begin{abstract}
El artículo busca explicitar uno de los trabajos referidos a una línea de investigación más amplia cual es la relación entre psicología y tecnología. Lo anterior es relevante, ya que no es posible concebir contemporáneamente al sujeto psicológico fuera de un mundo colonizado por las máquinas, representando ellas su condición de posibilidad. Por tanto, la premisa central busca describir algunas de las consecuencias que el marco actual de las transformaciones tecnológicas tiene con relación al sujeto; ya que el vínculo sujeto/máquina en cuanto fuente productora de subjetividades constituye un desafío para la psicología.

Palabras clave: Subjetividad, tecnología, máquina.
\end{abstract}

\begin{abstract}
The article seeks to explicit one of the works referred to a broader line of investigation about the existing relationship between psychology and technology. Its relevance relies on the fact that is currently no longer possible to conceive the psychological subject outside of a world colonized by machines which represent its condition of possibility. Since the bond subject / machine as a producing source of subjectivities is a challenge for psychology, the central premise of this work seeks to describe some of the consequences that the current frame of technological transformations has in relation to the subject.

Key words: Subjectivity, technology, machine.
\end{abstract}

La premisa central del artículo consiste en describir algunas de las consecuencias que el marco de las transformaciones tecnológicas tiene con relación al sujeto; ya que el vínculo sujeto/máquina en cuanto fuente productora de subjetividades constituye un desafio para la psicología.

Ahora bien, lo primero a concebir es la forma en que se relacionan las teorías sociales con la psicología. Es decir, para poner en conexión los patrimonios tecnológico y cultural con el sujeto es menester hacer emerger la forma de articulación entre individuo y sociedad en una perspectiva psicológica. Es posible afirmar incluso que dependiendo de las maneras en que se establezca este vínculo, la interdependencia Sujeto/Máquina se configurará en un escenario múltiple y tendrá consecuencias diferentes. De allí que la primera dimensión a tratar sea, justa-

\footnotetext{
* Psicóloga, Licenciada en Psicología, Universidad de Chile. Magíster en Psicología Social y de la Personalidad, Universidade Federal de Rio de Janeiro. Doctora en Filosofía, mención Epistemología de la Ciencias Sociales, y Psicología (c), Universidad de Chile. Correspondencia: Universidad Santo Tomás (Sede Talca), Av. Carlos Schorr 255. Talca-Chile. FonoFax: 071226515 - 071 226756 - 071 233686. E-mail: yvalenzuela@ust.cl
}

mente, las sobredeterminaciones que existen en el abordaje de la relación entre teorías sociales y psicología. La pregunta allí, por lo tanto, es ¿de qué forma es posible conectar las representaciones culturales, el escenario de la interactividad como el entorno humano de la relación mediada del Sujeto/Máquina con las transformaciones del sujeto psicológico? Para poder responder es factible adentrarse en las formas en que la psicología establece su articulación con las teorías sociales, vale decir, las maneras de interpretar la interdependencia entre individuo y sociedad.

Por otra parte, si se asume que la relación Sujeto/Máquina es una de las formas que hoy adquiere la tensión individuo y sociedad, entonces es posible señalar que los cambios acontecidos con el sujeto psicológico están insertos dentro de ese horizonte. Es decir, la relación Sujeto/Máquina se constituye, también desde este punto de vista, una totalidad histórica, ahora vista en el sentido de emerger como un principio explicativo en la noción histórica de sujeto psicológico. Inclusive desde allí es viable afirmar una segunda premisa: el que hoy existe una explosión de la categoría de sujeto psicológico 
en un doble sentido, tanto en cuanto al rompimiento e insostenibilidad de sus antiguos contenidos como en virtud de la explosión de nuevas iluminaciones a partir de los cambios ocurridos entre sujetos y máquinas. En una expresión extrema es dable llegar a decir que no hay en la contemporaneidad sujeto psicológico posible de ser pensado por fuera de las formas de relación Sujeto/Máquina. Ahí precisamente reside la enorme relevancia de su estudio para la psicología.

Consecuentemente, el tercer punto abordado es la descripción sucinta de algunas formas en que la relación Sujeto/Máquina está provocando, gestando, produciendo subjetividades. Todo lo expuesto sirve de base, de horizonte de referencia, para entender los procesos de virtualización del sujeto no como una oposición sino como una concreción de lo real y comprender también, la relación Sujeto/Máquina como artefactos protéticos en cuanto unidad en la discordia, totalidad desgarrada, contradicción tensional indisoluble; que constituye una clave y un desafío actuante para la psicología ya que, usando el sentido que le otorga Foucault: "la renovación radical de la psicología como ciencia del hombre en sus nexos con lo social no es simplemente un hecho histórico en el cual se puede situar el desarrollo de los últimos cien años, sino que todavía constituye una tarea incompleta a cumplir que sigue abierta enteramente en la orden del día" (Foucault, 1994, p. 125).

Luego, el orden de la exposición será el siguiente:

1. El vínculo entre teoría social y psicología

2. La explosión del sujeto psicológico

3. La producción de subjetividades

\section{El vínculo entre teoría social y psicología}

En psicología, la categoría de sujeto, tal como reconocerán diversos enfoques, es central. Sin embargo, no en todos ellos los nexos constitutivos del sujeto en sus relaciones sociales se consideran parte del estudio de la psicología. Este tipo de visión entrega la ilusión de la posibilidad del establecimiento de una frontera demarcada entre individuo y entorno, una especie de revisitación aristotélica donde el conte- nido de profesiones y oficios fuera delineado por semejanza y diferencia específica ${ }^{1}$.

Sin embargo, como sostendrán diversos autores, entre ellos Lacan (1977), en el sujeto ya están involucrados sus lazos con el sistema. No existe curación posible sin considerar la relación sujeto/entorno (Foucault, 1966). Uno de los nudos centrales en esta red, es la relación sujeto/máquina, ya que desde allí se deben definir códigos psicológicos de interpretación y además aparece como una potencial herramienta de curación por su posibilidad de desalienación.

Este diagnóstico complejo es tan relevante para la psicología como las alianzas existentes entre teoría social y psicología en el estudio de la personalidad autoritaria ${ }^{2}$, ya que hoy la relación sujeto/máquina conforma una pauta "amplia y coherente, cual si estuvieran unidas por una mentalidad o espíritu común; esta pauta es la expresión de profundos impactos en la personalidad de los individuos"' (Adorno y otros, 1965, p. 27). Si en la actualidad, diversos autores concuerdan que el diagnóstico sociopsicológico contemporáneo apunta más a una desestructuración del superego, el análisis no sólo de la estructura psicológica del individuo sino tensada en la situación de objetivación del sistema maquinístico en que vive se vuelve crucial para la psicología.

En la medida en que discurren una junto a otra sin vincularse entre sí, la ciencia de la sociedad y la de la psiquis sucumben por igual a la sugestión de proyectar en su materia la divi-

\footnotetext{
${ }^{1}$ En su enfoque más característico, esta perspectiva postula que las ciencias sociales se ocupan del sujeto y sus relaciones sociales (semejanza entre ellas) y la psicología de los aspectos relativos al individuo (diferencia específica).

2"El estudio de la personalidad autoritaria trata sobre la discriminación social. Su propósito, empero, no es el de añadir simplemente nuevos descubrimientos empíricos a conocimientos amplios. El tema central de la obra es la aparición de una especie antropológica que denominamos el tipo humano autoritario. Es, a un mismo tiempo, un ser ilustrado y supersticioso, orgulloso de su individualismo y constantemente temeroso de ser diferente a los demás, celoso de su independencia y proclive a someterse ciegamente al poder y a la autoridad. La estructura de carácter que comprende estas tendencias opuestas ha atraído la atención de filósofos y pensadores politicos. Este libro encara el problema con los medios que nos brinda la investigación sociopsicológica".

ADORNO, Theodor y otros. "LA PERSONALIDAD AUTORITARIA". Editorial Proyección. Buenos Aires, 1965. Pág. 19.
} 


\section{LA RELACIÓN SUJETO/MÁQUINA COMO PRODUCTORA DE SUBJETIVIDADES}

sión del trabajo del conocimiento ${ }^{3}$. Ciertamente, ni siquiera la forma de conducta narcisista del psicótico carece de un aspecto social. Se puede, claro está, construir determinados tipos de enfermedad mental siguiendo el modelo de una sociedad enferma, pero como ya lo ha demostrado Foucault, los límites entre lo externo y lo interno no sólo son difusos sino cambiables históricamente y, por tanto, ineludiblemente sobredeterminados ${ }^{4}$.

No es asunto de mera terminología el ampliar o no el concepto de sujeto en el ámbito psicológico. No es casualidad que el psicoanálisis fuera concebido en el ámbito de la vida privada y los conflictos familiares: éstos son sus dominios, porque el propio juego de las fuerzas psicológicas está bastante restringido al sector privado, teniendo menor poder sobre la esfera de la producción material. La separación entre los actos sociales en que se reproduce la vida de los seres humanos y ellos mismos les "impide llegar a ver el engranaje y los deja en manos de esa frase según la cual la cuestión serían los seres humanos mismos, que anteriormente nunca los había consumido en las mismas proporciones que en la época de la cadena de montaje" (Adorno, 1991, p. 154).

Lo que despliega el velo social es el hecho que las tendencias sociales se imponen sobre los sujetos y éstos no las reconocen como suyas. "Se vuelven ciegos para ver la forma invisible del conjunto, no ven que la sociedad es tanto su

\footnotetext{
3"La separación entre sociedad y psiquis en falsa conciencia, eterniza en forma de categorías la escisión entre el sujeto viviente y la objetivación que impera sobre los sujetos y que, no obstante, ellos producen. Pero no se le puede quitar el terreno a esa falsa conciencia sólo por un decreto metodológico". ADORNO, Theodor. "ACTUALIDAD DE LA FILOSOFÍA”. Editorial Paidós. Barcelona, 1991. Pág. 139.

4 "Quizá llegue un día en que no se sepa bien lo que ha podido ser la locura. Su figura se habrá cerrado sobre sí misma no permitiendo descifrar ya los rastros que haya dejado. Esos trazos formarán parte de configuraciones que nosotros no sabríamos designar, pero que en el porvenir serán las rejas indispensables para hacer que resulten legibles nosotros y nuestra cultura. Artaud pertenecerá al suelo de nuestro idioma y no a su ruptura, las neurosis a las formas constitutivas y no a las desviaciones de nuestra sociedad. Todo lo que hoy sentimos sobre el modo del límite o de la extrañeza, se habrá reunido con la serenidad del sistema. Y aquello que para nosotros hoy designa el Exterior un día acaso llegue a designarnos a nosotros". FOUCAULT, Michel. "HISTORIA DE LA LOCURA EN LAÉPOCA CLÁSICA". Tomo II. Editorial Fondo de Cultura Económica. México, 1967. Pág. 328.
}

misma médula como su contrario. Lo inescrutable de la objetividad enajenada es que arroja a los sujetos de vuelta a sus limitados sí mismos, y pone ante ellos en una imagen de espejo su escindido ser para sí, el sujeto monadológico y su psicología, como si fuera lo esencial" (Adorno, 1991, p. 154).

Lo paradójico de esta contradicción es que sea la ciencia, que tiene como horizonte develar el significado del sujeto, la que los transforme, por su propia configuración, una vez más, en objeto. Esta dialéctica afecta no sólo al comportamiento del sujeto con el mundo exterior, sino también al sujeto en cuanto tal. El mecanismo de adaptación a un medio encasillado, encasilla también al sujeto ya que "el sujeto se descompone en una maquinaria de producción social que se prolonga en su interior" (Adorno, 1991, p. 164). De esta forma, el concepto del Yo es dialéctico, psíquico y no psíquico, un fragmento de libido y un representante del mundo.

En la relación Sujeto/Máquina estos nexos entre teoría social y psicología se vuelven una clave de enunciación relevante ya que posibilitan el cruce de lo que el hombre hace con lo que ha hecho de él.

De esta manera, el desafío inacabado de la psicología es adentrarse en los nexos de la relación individuo y sociedad sin soltar la tensión en beneficio de la identidad o la total separación de esos componentes. De allí que Adorno defina la tensión de esa relación como una unidad en la discordia, ya que si bien el individuo no es simplemente individuo y sustrato de una psicología sino que al mismo tiempo es sustento de definiciones sociales que lo troquelan, también se debe considerar la imposibilidad de explicar psicológicamente lo que no surge en absoluto de la vida psíquica del ser humano individual (Adorno, 1991). A su vez, lo anterior puede ser visto como una evidencia en el sentido epistemológico ya que "el conocimiento no tiene poder para otra totalidad que la antagónica y sólo en virtud de la contradicción es capaz de alcanzar alguna totalidad" (Adorno, 1991, p. 150).

De allí que ese postulado de Adorno resignifique la clásica sentencia hegeliana acerca del peligro de la absolutización de un componente convirtiéndolo en una totalización: "Hegel reconoció la preeminencia del todo con respecto a sus partes finitas y contradictorias cuando se las confronta con él; pero ni derivó una metafisica del principio de la totalidad ni 
glorificó al todo, de igual forma que no independizó las partes frente al todo, como elementos suyos, sabía perfectamente el crítico del Romanticismo que el todo sólo se realiza a través de las partes, únicamente a través de la desgarradura" (Adorno, 1981, p. 18).

Eagleton (1966) apunta en este mismo sentido al describir, en su ideología de la estética, la noción de la necesidad de la totalidad para comprender los fragmentos en cuanto toda parte requiere del todo como referente: "Hegel sabía que cuando se habla de diferencia se requiere de la totalidad, ya que cuando la diferencia en cuestión se torna pura se vuelve nada. Como pura diferencia no hace ninguna diferencia, ella es una simple señal de ausencia, ya que aquello que no puede ser nombrado no puede ser violado" (p. 91).

De este modo, la crítica hegeliana a los mecanismos de absolutización se vuelve un desafio para toda profesión que busque comprender las contradicciones del todo social en las relaciones tensionales existentes entre individuo y sociedad. Es más, si analizamos las exigencias de Hegel con relación al ideario del iluminismo, aparece la posibilidad de hacer válidos para la psicología esos mismos requisitos: Hegel está convencido que la época de la Ilustración que culmina en Kant y Fichte no ha erigido en la razón sino un ídolo porque ha sustituido equivocadamente la razón por el entendimiento o la reflexión y con ello ha elevado a absoluto algo finito (Habermas, 1989). De allí que se proponga criticar esa absolutización mostrando que una razón tiene que ser capaz de articular tensionalmente aquellas oposiciones de la razón, la cual al proceder discursivamente, no tiene más remedio que generar.

Allí es importante destacar dos cosas: que entonces el problema de la Ilustración es cómo obtener normatividad a partir de sí misma y el que sólo el elemento de la vida pública puede transformar la fe en religión y prestar a la razón eficacia práctica. La denuncia realizada por Hegel es, entonces, la de la positivización: "positivistas llama Hegel a las religiones que sólo fundan su autoridad y que no ponen el valor del hombre en la moral de éste, positivistas son los preceptos conforme a los cuales los creyentes han de conseguir el beneplácito divino por las obras en vez de por una acción íntegramente moral, positiva es la esperanza de la recompensa en el más allá, positiva es la separa- ción de una doctrina en manos de unos pocos respecto a la vida y propiedad de todos, positivas son las garantías y amenazas que tienen como meta la simple legalidad de la acción; positiva es, en fin, sobre todo la separación entre religión privada y vida pública" (Habermas, 1989, p. 40).

De este modo, Hegel sostiene contra los ilustrados que la religión racional pura, no menos que la fe fetichista, representa una abstracción, pues es incapaz de interesar el corazón y el espíritu del hombre. Esta ilustración es sólo el reverso de la ortodoxia (Habermas, 1989). Es de allí que se deriva el carácter represivo de la razón que, por tanto, es preciso redimensionar ya que en el mundo moderno la emancipación tiene que trocarse en ausencia de libertad porque la desencadenada fuerza de la reflexión se ha autonomizado y sólo genera ya unificación mediante la violencia de una subjetividad represora.

Así, para Hegel la razón debe pensarse no como oposición abstracta de lo finito y lo infinito sino como autorrelación absoluta de un sujeto que lleva en sí tanto la unidad como la diferencia de lo finito y lo infinito. Luego, el absoluto no es concebido ni como sustancia ni como sujeto, sino sólo como el proceso mediador de la autorrelación que se produce a sí misma exenta de toda condición (Habermas, 1989). Este dilema acompaña al proyecto iluminista desde dentro y debe ser vivido tensionalmente como su propia desgarradura, sin intentar eliminar esa contradicción a riesgo de suprimirse a sí mismo.

Consecuentemente, la no absolutización, el evitar volver infinito algo finito, el no caer en la positivización; entendidos como mecanismos epistemológicos para hacer emerger las contradicciones, pueden ser vistos como requisitos establecidos al interior de la psicología para entender el nexo entre individuo y sociedad. De este modo, queda expuesta "la pretensión de la psicología al ensanchar su feudo hasta abarcar la totalidad como un error que contenía el elemento de falsedad tanto del psicoanálisis como del conductismo" (Adorno, 1991, p. 150). De allí que es posible sostener que el psicologismo en cualquiera de sus formas es ideología, ya que "transforma por ensalmo la forma individualista de socialización en definición extrasocial, natural, del individuo. El peligro de la absolutización de la razón en el Iluminismo, sólo ha cambiado esencialmente de escenario. En cuanto se explica como algo basado en el 
psiquismo, los procesos sociales se vuelven cosificados puesto que, abstraídos de sus tendencias históricas, hasta sus cualidades psicológicas promedio van a insertarse como explicación en su comportamiento social promedio" (Adorno, 1991, p. 158).

La relevancia de lo anterior para este trabajo radica en que "cuanto más estrictamente se piensa el ámbito de lo psicológico como un campo de fuerzas autárquico cerrado en sí mismo, tanto más se desubjetiviza la subjetividad y el psiquismo arrojado de vuelta a sí mismo, casi sin objeto, se vuelve inmóvil como un objeto" (Adorno, 1991, p. 169). Por tanto, una psicología pensada así, no puede romper su inmanencia sino que se agota en sus propias ecuaciones: "ya que el psiquismo es sólo un tanteo a ciegas en pos de lo que él mismo no es. El peligro de lo anterior radica en que este estado de cosas no se da sólo en la teoría del conocimiento sino que se prolonga en los resultados de la terapia, en esos seres humanos desesperadamente ajustados a la realidad que se han remodelado literalmente como aparatos para poder abrirse paso con más éxito en su restringida esfera de intereses. En cuanto la conceptualización psicológica sigue procediendo así, se toma su venganza en ella la divergencia tan descuidada entre psicología y sociedad" (Adorno, 1991, p. 169).

Ciertamente, la prácticas designan un espacio conceptual y se sitúan en él. Toda intervención es capturada a partir de una forma de ver ${ }^{5}$. Por tanto, dependiendo de cómo se realice el nexo entre individuo y sociedad, la conceptualización y las prácticas psicológicas harán emerger distintos y limitados enfoques de la relación Sujeto/ Máquina ya que ella está indisolublemente anclada en las formas de esa tensión.

\section{La Explosión del Sujeto Psicológico}

En el centro del debate contemporáneo se encuentra la noción de sujeto. Esta asume diversas vertientes de discusión y crítica: desde la idea de muerte del sujeto y su reemplazo por el lenguaje a la virtualización del sujeto como oposición a lo real o al consecutivo desaparecimiento

\footnotetext{
5"La clínica es a la vez un nuevo corte del significado, y el principio de su articulación en un significante en el cual tenemos la costumbre de reconocer, en una conciencia adormecida, el lenguaje de una ciencia positiva". FOUCAULT, Michel. "EL NACIMIENTO DE LA CLÍNICA" Editorial Siglo XXI. México, 1966. Pág. 7.
}

del sujeto psicológico. Lo que se sostiene, es que más que una extinción, asistimos a la explosión del sujeto psicológico en dos sentidos: en cuanto explosión e imposibilidad de seguir usando el contenido que conformaba dicha categoría y, a la vez, aparecimiento explosivo de consideraciones en su interior relativas a las formas de relación del sujeto y la máquina.

Así, es posible afirmar, que "los contenidos de la subjetividad dependen, cada vez más, de una infinidad de sistemas maquínicos" (Guattari, 1993, p. 177). Esto no significa que, necesariamente, porque las máquinas sean capaces de articular enunciados y registrar estados de ánimo al ritmo de nanosegundos, esto haga de ellas potencias satánicas dispuestas a dominar al hombre (como se piensa en ciertos postulados agonales del hombre y la máquina). Lo que sí evidencia la presencia maquínica en la contemporaneidad es que "no tiene sentido que el hombre quiera desviarse de las máquinas ya que ellas no son otra cosa más que formas hiperdesarrolladas e hiperconcentradas de ciertos aspectos de su propia subjetividad" (Guattari, 1993, p. 178).

Consecuentemente, es posible entender que existe un doble puente del hombre en dirección a la máquina y de la máquina en dirección al hombre, que en verdad nos remite nuevamente al planteamiento de esa tríada interactiva donde la máquina es lo que media la relación entre dos sujetos. Si esto se entiende es posible comprender que todos los sistemas maquínicos sea cual fuere el dominio al cual pertenecen (técnico, semiótico, lógico, etc.) son soportes o sobredeterminaciones que influyen y califican los procesos de la producción de subjetividad.

Así, la subjetividad aparece como plural, polifónica y multicausal. Sin embargo, esto no significa necesariamente que esos grandes movimientos de subjetivación tomen un rumbo emancipador. Tal como lo ha planteado Habermas (1990), entre otros, muchas reivindicaciones en este plano evidencian una "reterritorialización conservadora de la subjetividad" (p. 14). Los integralismos en diversos continentes, la xenofobia, las pruebas nucleares, la guerra del Golfo y, en general, los tipos de evento desastrosos que han sido mediados por la máquina desactivan lo suficiente los clásicos contenidos de la noción de sujeto psicológico. Esto no es relevante sólo para la psicología, ya que ante el actual estado de cosas la so- 
ciología, la economía y el derecho, se encuentran bastante mal provistas para dar cuenta de los híbridos movimientos de la subjetividad hoy. "Por su parte, el psicoanálisis tradicional no está mejor ubicado para afrontar estos problemas y en estas condiciones parece más oportuno forjar una concepción más transversalista de la subjetividad que permita responder a la vez de sus colisiones territorializadas y de sus aperturas a sistemas de valor" (Guattari, 1996, p. 14).

De esa forma, incluso las máquinas tecnológicas de información y comunicación operan en el corazón de la subjetividad porque actúan, no únicamente a nivel de sus memorias, de su inteligencia, sino también se tornan en componentes de su sensibilidad, sus afectos y sus fantasmas. Por ello, la consideración de estas dimensiones maquínicas de subjetivación permite insistir acerca de la heterogeneidad de los mecanismos que agencian la producción de subjetividad. Entre ellos encontramos componentes semiológicos significantes manifestados a través de la familia, la educación, el arte, el deporte; elementos fabricados por la industria de los medios de comunicación y dimensiones simbólicas derivadas de las máquinas informacionales de signos.

La evidencia anterior nos obliga, en cierta forma, a considerar la tensión entre una tendencia a la homogeneización universal y reduccionista de la subjetividad junto con el reforzamiento de la heterogeneidad y la singularización de sus componentes. Así, surge una cierta ambiguedad de esa contradicción: el que la producción maquínica de subjetividades puede trabajar tanto para el progreso humano como para su regresión. Por ello, la evolución maquínica no puede ser juzgada positiva o negativamente sino considerando sus sobredeterminaciones ${ }^{6}$.

Esto es relevante especialmente para la psicología en cuanto permite mostrar cómo la subjetividad no se engendra sólo de la psiquis. En

\footnotetext{
"Lo mejor es la creación, la invención de nuevos universos de referencia; lo peor, la masmediatización embrutecedora a la que millones de individuos están hoy condenados. Las evoluciones tecnológicas, aunadas a experimentaciones sociales en estos nuevos ámbitos, tal vez puedan librarnos de la etapa opresiva actual y hacernos entrar en una era postmediática caracterizada por una reapropiación y una resingularización del uso de los medios de comunicación". GUATTARI, Felix. "CAOSMOSIS". Editorial Manantial. Buenos Aires, 1996. Pág. 16.
}

este sentido, el trabajo de Stern explora de manera notable las formaciones subjetivas preverbales del niño, mostrando que no se trata de estadios en el sentido freudiano, sino de niveles de subjetivación que persistirán de forma paralela durante toda la vida (Stern, 1985). De este modo, esta perspectiva renuncia a la ponderación excesiva de "la psicogénesis de los complejos freudianos presentados como universales estructurales de la subjetividad" (Stern, 1985, p. 97). Aquí se pone de relieve, además, el carácter transubjetivo de las experiencias precoces del niño en una dialéctica que estructura las fases emergentes de la subjetividad y que no dejará de reaparecer en el sueño, el delirio, la exaltación creadora o el sentimiento amoroso.

En este mismo sentido, los trabajos en algunas clínicas de psicoterapia no se plantean ya una simple remodelación de la subjetividad de los pacientes sino la constitución de complejos de subjetivación más globales (individuo, grupo, máquinas, intercambios múltiples) que ofrecen a la persona posibilidades diversas de rehacerse, salir de sus atolladeros repetitivos y, en cierto modo, resingularizarse creando nuevas modalidades de subjetivación. Dado este contexto, los componentes más heterogéneos pueden concurrir tanto a la evolución positiva del paciente, como a la inclusión social de sectores de excluidos ${ }^{7}$ : relaciones con el espacio arquitectónico, con máquinas de diverso orden, que pueden incluso provocar nuevos vínculos económicos aprovechando en todas las ocasiones la nueva relación establecida entre el individuo y la máquina como vías de apertura al exterior y mecanismos de reindividuación.

Ahora bien, las condiciones de producción esbozadas en estas redefiniciones involucran la interacción entre diversas instancias de lenguajes, de formas económicas, interacciones institucionales y dispositivos maquínicos como los basados en la asistencia por computadores (acceso a bancos de datos, videotecas, videoconferencias, conversaciones vía Internet). Lo anterior repercute en el propio concepto de inconsciente en cuanto hoy no es posible disociar esa teoría de estas nuevas formas complejas de producción de subjetividad.

\footnotetext{
${ }^{7}$ Un trabajo que apunta en esta dirección son los cursos de capacitación en informática que ofrece la Legião da Boa Vontade en Rio de Janeiro, donde un gran porcentaje de alumnos son "moradores de rua".
} 


\section{LA RELACIÓN SUJETO/MÁQUINA COMO PRODUCTORA DE SUBJETIVIDADES}

Indiscutiblemente, los descubrimientos freudianos (que habría que calificar de invenciones) enriquecieron los ángulos en la forma de abordar la psiquis, pero no se puede caer en el peligro de concebirlos como mecanismos reales de operación. La idea de invención está colocada aquí en el mismo sentido en que los cristianos produjeron nuevas formas de subjetivación, la caballería cortés y el romanticismo inventaron un nuevo amor o el marxismo inventó un nuevo sentimiento de clase. Asimismo, las diversas interpretaciones freudianas segregaron nuevas maneras de ver y hasta de producir la histeria, la neurosis infantil, la psicosis, la conflictividad familiar, la lectura de los mitos. Incluso, en su versión más estructuralista, el propio inconsciente freudiano evolucionó en el curso de su historia perdiendo parte de su riqueza y la tensión de su contradicción, pasando a centrarse en el análisis del yo, la adaptación a la sociedad o la conformidad con un orden significante.

Ahora bien, el problema ya no es saber si el inconsciente freudiano o lacaniano aportan una respuesta científica a los problemas de la psiquis sino entender que estos modelos construidos deben ser considerados interdependientemente y en sus propias transformaciones con toda la serie compleja de dispositivos maquínicos de producción de subjetividad. De forma más general, deberá admitirse que cada individuo, cada grupo social vehiculiza su propio sistema de modelización de subjetividad, es decir, movimenta una cierta cartografía hecha de puntos de referencia múltiples a partir de la cual cada uno se posiciona en relación con sus afectos, sus angustias y su razón, derivando en ese lugar movible del mundo en que transcurre nuestra existencia.

Por tanto, lo que se sostiene es que sólo la interacción de estas cartografías dará un régimen de la mirada mediante el cual sea posible describir las diferentes conformaciones de la subjetación. Ya no existe la posibilidad de expresar en una de estas perspectivas lo que se podría denominar un conocimiento objetivo de la psiquis. Es justamente en este punto donde se evidencia la relevancia tanto de los planteamientos hegelianos acerca de la no absolutización de un componente de la totalidad como de las reflexiones de Adorno acerca de la tensión entre individuo y sociedad y el cómo poner en relación las teorías sociales y la psicología.
Lo anterior no reviste solamente un carácter discursivo sino que se plantean una serie de ámbitos prácticos: "Los conceptos de inconsciente que se nos proponen en el mercado del psicoanálisis ¿se adecuan a las condiciones actuales de producción de subjetividad? ¿Se los utiliza como grilla de lectura global y exclusiva y de pretensión científica, o como instrumentos parciales que entran en composición con otros, siendo el criterio último de orden funcional? Esto es relevante porque, de cierta forma, el inconsciente freudiano es inseparable de una sociedad apegada a su pasado, a sus tradiciones falocráticas, a sus invariantes subjetivas; y las conmociones contemporáneas reclaman sin duda una modelización más orientada hacia el futuro y a la aparición de nuevas prácticas" (Guattari, 1996, p. 23).

En consecuencia con lo anterior, es menester preguntarse por la validez de la permanencia del dualismo consciente-inconsciente en las tópicas freudianas y todas las oposiciones (a veces incluso interpretadas maniqueístamente) correlativas de la triangulación edípica y del complejo de castración. Una de las posibilidades de renovación, siguiendo la argumentación de Guattari (1996), sería: “optar por un inconsciente que superpone múltiples estratos de subjetivaciones, estratos heterogéneos de extensión y consistencia variables, más vuelto hacia praxis actuales que hacia fijaciones y regresiones sobre el pasado. Inconsciente de flujos $y$ máquinas abstractas más que inconsciente de estructura y lenguaje" (p. 24).

No se trata de compartir o no lo sostenido por dicho autor, lo importante ni siquiera es el contenido final de su propuesta, sino la importancia de concebir un método cartográfico multicomposisional que pueda comprender de mejor modo los procesos de subjetivación y que dé como resultado una reapropiación de los mecanismos de producción de la subjetividad. Este es un dilema crucial para la psicología contemporánea en cuanto pretende conocer el significado que ese sujeto le atribuye al mundo y sus relaciones. Esto se relaciona con las formas temporales de entender la producción de subjetividades, ya que como lo sostiene Bakhtin (1995), "la polifonía de los modos de subjetivación corresponde, en efecto, a una multiplicidad de maneras de vencer al tiempo" (p. 37). Lo anterior no sólo dice relación con lo planteado en la dimensión acerca de los aspec- 
tos temporales, como la aceleración, el peligro de ser excluido del tiempo o su virtualización, sino que se relaciona también con la polifonía como mecanismo de exploración múltiple, cuyo desafio e impulso ha estado presente desde su origen.

Ahora bien, ¿cómo es posible reunir esos componentes de subjetivación sin perder su diversidad?: gracias a la idea de foco, de motivo, de ritornelo. En este sentido, ese atractor, ese código de lectura, permite que los componentes sean captados en forma inteligible conservando su heterogeneidad. Desde estas consideraciones se podría entender lazos hacia el sentido de lo descrito en relación con la identidad neurótica o la psicosis.

Ello también es imperioso para poder entender las transformaciones sociales contemporáneas como mutaciones múltiples de subjetividades, "de subjetividades parciales, polifónicas, colectivas y maquínicas" (Guatarri, 1996, p. 35). De todo lo anterior se deriva la enorme relevancia de renunciar a perspectivas totalizantes en los enfoques psicológicos, de allí que la producción de subjetividades se verá afectada intensamente por las formas de relación entre teoría social y psicología, así como los mecanismos de interconexión entre individuo y sociedad.

Si la psicología quiere dar cuenta de estas formas multicausales de producción de subjetividades, ha de considerar, por tanto, rigurosamente el contenido de esta explosión del sujeto psicológico, tanto en el sentido de realizar una resignificación crítica de los modelos y el horizonte en que la noción de sujeto psicológico ha aparecido en sus diversos enfoques clásicos, como asumir el desafío de encontrar formas polifónicas de comprender y explicitar los mecanismos múltiples de producción de subjetividades que se encuentran enteramente permeados, contemporáneamente, por los avatares de la relación Sujeto/Máquina.

\section{La Producción de Subjetividades}

La producción de subjetividad se encuentra sobredeterminada multicausalmente. Más aun, podríamos decir que existen diversas dimensiones, diferentes ámbitos donde se recrean los nexos de interdependencia de la subjetividad con el contexto. Sin embargo, esto no quiere decir que cualquier subjetividad emerja con igual fuerza. Existen, por así decirlo, locus privilegiados donde estas subjetividades se moldean.
Uno de ellos, es una cierta revisitación del ideario de oposición hombre/máquina donde este nexo es visto peligrosamente y donde la concepción maquínica queda reducida y opuesta frente a la figura de lo humano. En este sentido, este prisma ayudaría a la continuación de un imaginario dual, algo así como viejas leyendas para un mundo nuevo. Con ello, se producirán dos consecuencias básicas; la reducción de la complejidad social en versiones unívocas y el no-reconocimiento, tanto de la ambigüedad paradojal de la relación Sujeto/Máquina, como de su necesaria triangulación entre sujetos en el ámbito de la interactividad.

En las últimas dos décadas ha tomado consistencia en ciertos medios intelectuales, sobre todo en aquellos conocidos genéricamente bajo la denominación de humanidades, una cierta concepción de la técnica como algo fundamentalmente extraño al hombre. Allí, las máquinas y las maneras de producción que las ponen en movimiento serían, sin lugar a duda, "algo que el propio hombre produce, algo que amplía y extiende sus sentidos y su capacidad de comprensión pero, al mismo tiempo, algo que se le escapa como arena entre los dedos y en lo cual él ya no se puede reconocer" (Simondon, 1969, p. 87).

Asimismo, toda una literatura de ficción trae la caricatura de esa idea bastante diseminada según la cual, la proliferación de máquinas cada vez más potentes, versátiles e inteligentes estaría colocando en peligro la propia identidad humana. Como lo sostiene Couchot: "ese sentimiento es tanto o más doloroso si concebimos al hombre como un animal desnudo, desprovisto de cualquier otra prótesis instrumental que no sea su lenguaje, el único que fundaría su humanidad" (Couchot, 1988, p. 87). Ahora bien, fuera del lenguaje -que no deja de ser una tecnología, incluso tal vez la más avanzada de todas las practicadas por el hombre- todas las demás prótesis de acción o percepción humana serían encaradas como artificiales y, por consecuencia, excluidas del universo de la cultura en cuanto territorio de lo humano.

Esta revisitación de posicionamientos clási$\cos$, de antagonismos hombre/máquina, repercute en una serie de ámbitos, ya sea de las relaciones de trabajo bajo el fantasma de la sustitución, en los mecanismos de comunicación y acceso bajo la forma de la exclusión, en el mercado como posesión o expectativa de consumo, en las calles como instrumento de control y tam- 
bién como imaginarios poblados de miedos en expresiones maquínicas propias del año 2000 , donde si bien este horizonte simbólico encuentra sus raíces en un pasado lejano, el contenido de su inseguridad se plasma en mecanismos tecnológicos de última generación. Ejemplos de esto encontramos diseminados en diversos espacios: miedo de que las personas no se relacionen más cara a cara sino solamente a través de Internet, miedo de que los avances sean tan grandes y rápidos que no se pueda acompañarlos, miedo de la excesiva humanización de las máquinas, miedo de que los niños sólo jueguen con máquinas y no desarrollen habilidades sociales, miedo a que el trabajo acabe o quede sólo en las manos de las máquinas.

En todo ello es posible diferenciar los contenidos pero a la vez, identificar una misma lógica binaria y antagónica de argumentación: la oposición entre hombre y máquina. Este tipo de pensamiento podría ser calificado de esencialista en dos sentidos: en cuanto se sustenta en una idea de esencia humana predeterminada como opositora de la máquina y también en cuanto constituye parte de un discurso inserto más bien, en un tipo de creencia, de adhesión de fe que en un razonamiento argumental.

De esta forma, dicha oposición se vuelve expresión de un imaginario mítico donde la máquina conspira todo el tiempo contra lo que restaría de esencia en la humanidad. Así, se da lugar a pensar que "en un tiempo y en un lugar en que las máquinas usurpan las actividades creadoras y en las cuales la mediación técnica se vuelve una fuerza generalizante, poco hay para hacer, a no ser filosofar sobre la propia impotencia" (Machado, 1996, p. 10). También es posible concebir a la máquina como locura y engendrar un malestar en términos de la preocupación por la relación del ser humano contemporáneo dudando de la esencia humana que saldría incólume de allí. Este malestar con la máquina se sustenta, por otra parte, en la idea de máquinas cada vez mejores con un ser humano de una cualidad cada vez peor, donde las imágenes de esta contradicción están presentes desde el pensamiento teológico al ético-moral.

Lo interesante, en términos de la psicología, es que este imaginario se ha vuelto casi un sentido común extendido y por tanto es posible que algunos individuos se vean y sean vistos como hombres expulsados de un paraíso maquínico, en el sentido de Ciorán: arrojados del tiempo.
No sólo es posible pensar lo anterior simbólicamente, la propia dialéctica de la modernización nos proporciona imágenes y datos de los mecanismos maquínicos de exclusión.

Este ideario amenazante adquiere ribetes catastróficos en un discurso humanista donde se busca reinstalar una idea de naturaleza en oposición a la idea de lo artificial. El resultado es uniformar la pluralidad, intentar identificar la diversidad de las experiencias, cerrando los ojos para cualquier mecanismo que evidencie la articulación protética de hombres y máquinas o también condenando dichos nexos bajo juicios morales, estéticos o cognitivos.

A su vez, esta relación binaria olvida o reduce, positivizándola, la propia idea de humanismo. Como sostendrá Savater (1990), le juega una mala pasada a ese humanismo impenitente que configura su propia idea de humanidad en las conexiones indeterminadas con otros ámbitos como lo maquínico. Por tanto, la extrema contradicción es que esa visión unidireccional y esencialista del humanismo, al querer vengarse de la máquina, reduce al propio ser humano que quería enaltecer. De esta forma: "el modo de pensar esencialista, substancialista, es aquél que lleva a tratar las actividades o preferencias propias de ciertos individuos o de ciertos grupos de una cierta sociedad, en un determinado momento, como propiedades sustanciales, inscritas de una vez y para siempre en una especie de 'esencia biológica' o, lo que no es mejor, de una 'esencia cultural', que lleva a los mismos errores en la comparación no con sociedades diferentes pero sí entre períodos sucesivos de una misma sociedad" (Bourdieu, 1995, p. 1995).

De allí que el esencialismo se vuelva ese acuerdo tácito, pre-reflexivo, inmediato, sobre el sentido del mundo que es el fundamento y filtro de las experiencias presentes.

Consecuentemente, al ejercer una mirada positivizada de la relación Sujeto/Máquina, lo anterior también no tiene cómo hacer emerger los matices, los sesgos, las hibridizaciones, las multicausalidades, las polifonías de dicha relación que precisan ser equalizadas. En este sentido existe, sin duda, mucho de fetiche en esta actual revisitación de la relación hombre/máquina. A medida que estas últimas se vuelven más atrayentes y amigables, su efecto se tiende a tornar seductor y lisérgico, sobre todo en un público concebido como lo que Bell denomina 
el hombre sin atributos, para referirse a ese sujeto que en virtud de los procesos tecnológicos y modernizantes ha perdido sus referentes $\mathrm{o}$, como sostendrá Berger, ha quedado transformado en un paria dentro de un mundo sin hogar ${ }^{8}$. Así también las personas se deleitan (y algunas hasta se vician) apretando botones compulsivamente, haciendo zaping o jugando juegos de video. Los recursos interactivos de que ya disponen gran parte de las actuales máquinas ópticas y acústicas difundidas a nivel de gran público dan un carácter lúdico incluso a la respuesta simple de los movimientos de un operador en la medida que estas aparezcan en una tela bajo la forma de figuras multicoloridas.

Es así como se puede llegar a concebir que "las nanomáquinas además de consagrar una tecnología de los sensores, de los teleespectadores y de los microprocesadores consagraron también un espacio-sin-lugar, un lugar-sin-hogar. Y es, por tales indicadores, que hoy nos encontramos frente a un nuevo dios en que las cualidades de la ubicuidad, de la instantaneidad y de la facultad de ser al mismo tiempo omnipresente y omnividente nos encerró en el mundo de la farsa y donde nosotros mismos, reducidos a ser tan mediáticos como los propios aparatos de mediación, por atrofia, parálisis o incapacidad, no nos interesamos más por proyectar y construir cada momento de la historia" (Brasil Silva, 1998, p. 5).

Como se ha demostrado, el ideario dual y antagónico hombre y máquina no hace justicia a la descripción de dicha relación compleja y representa una cierta inadecuación de sus categorías conceptuales para intentar seguir el ritmo de alguno de los principales paradoxos que dicha articulación presenta en la sociedad contemporánea. Entre ellos es posible señalar el proceso de agudización de los sentidos, de multisensorialidad logrado por las máquinas en el sujeto a la vez que, justamente en virtud de la naturalización de estos mecanismos, las máquinas se vuelven invisibles haciendo, además,

\footnotetext{
${ }^{8}$ Para un análisis mayor al respecto ver:

BERGER, Peter y LUCKMANN, Thomas. "MODERNIDAD, PLURALISMO Y CRISIS DE SENTIDO. LA ORIENTACIÓN DEL HOMBRE MODERNO". Editorial Paidós. Barcelona, 1997.
}

la realidad más inmaterial ${ }^{9}$. Por último, un otro paradoxo posible de explorar se refiere a la doble condición de las máquinas digitales y los aparatos de multimedia en cuanto conjuntamente despliegan posibilidades de sonido, texto e imagen; unifican la representación sensorial en el código 0 - 1 .

Todo lo dicho puede mostrar, a grandes rasgos, que la matriz de un humanismo radical se cuela, insertándose en visiones de diverso signo político y conceptual, donde se hace precisa una resignificación aguda que dé lugar a una crítica efectiva de los mecanismos contemporáneos adoptados por la relación Sujeto/Máquina, pero donde no se reduzca lo humano a lo no-maquínico sino que se observe con cuidado las prótesis existentes en las cuales la máquina hace parte sustantiva de la propia humanidad. De allí que ampliar una línea de investigación que haga emerger la unidad de psicología y tecnología, permita resignificar no sólo los espacios de la clínica o las prácticas psicológicas, sino re-construir la propia dimensión de sujeto psicológico.

\section{Referencias}

Adorno, T (1981). Tres estudios sobre Hegel. Madrid: Taurus.

Paidós.

(1991). Actualidad de la filosofia. Barcelona:

Adorno, T., Frenkel-Brunswick E., Levinson. D.J. y Stanford, R.N. (1965). La personalidad autoritaria. Buenos Aires: Proyección.

Bakhtin, M. (1995). Lenguaje y polifonía. Barcelona: Anagrama.

Bourdieu, P. (1995). Razones praticas: Sobre a teoria da ação. Sao Paulo: Papirus.

Brasil Silva, S. (1998). Realidade digital: A globalização em fantasias. Brasilia: CNPq.

Couchot, E. (1988). L'odyssée, mille foise ou les machines a langage. París: Traverses.

Eagleton, T. (1966). A ideologia da estetica. Rio de Janeiro: Zahar.

Foucault, M. (1966). El nacimiento de la clínica. México: Siglo XXI.

(1967). Historia de la locura en la época clásica (Tomo II). México: Fondo de cultura económica.

(1994). Dits et ecrits (Vol. I). Paris: Gallimard.

\footnotetext{
9 "Como vemos, las cuestiones que se levantan desde los núcleos de especialistas en máquinas ya no son sólo cuestiones de física o de electrónica. Independientemente de su realidad material, las máquinas modernas poseen también una realidad abstracta, de orden lógico, matemático y lingüístico, una realidad que puede ser descrita como inmaterial".

GANASCIA, Jean-Gabriel. "A INTELIGÊNCIA ARTIFICIAL”. Editora Instituto Piaget. Lisboa, 1994. Pág. 17.
} 
Ganascia, J.G. (1994). A inteligência artificial. Lisboa: Instituto Piaget.

Guattari, F. (1993). Da produção de subjetividade. En A. Parente (Org.), Imagem máquina. A era das tecnologias do virtual (pp. 177-191). Rio de Janeiro: 34.

Guattari, F. (1996). Caosmosis. Buenos Aires: Manantial.

Habermas, J. (1989). El discurso filosófico de la modernidad. Buenos Aires: Taurus. (1990). Pensamiento postmetafisico. Madrid: Taurus.

Lacan, J. (1977). Escritos. Buenos Aires: Siglo XXI.

Machado, A. (1996). Máquina e imaginario. Sao Paulo: Editora da Universidade de São Paulo.

Savater, F. (1990). Humanismo impenitente. Barcelona: Anagrama.

Simondon, G. (1969). Du mode d'existence des objets téchniques. París: Aubier.

Stern, D. (1985). The interpersonal world of the infant. New York: Basic Book. 